\title{
NOVAS ABORDAGENS CURRICULARES A PARTIR DO DUA: APROXIMAÇÕES COM A EDUCAÇÃO ESPECIAL INCLUSIVA
}

\section{ELIZABETE CRISTINA COSTA-RENDERS* AUGUSTO SANTOS SILVA**}

\begin{abstract}
RESUMO
Trata da aplicação do design universal para aprendizagem (DUA) no atendimento educacional especializado junto aos alunos com dificuldades acentuadas de aprendizagem. Resulta de uma pesquisa de mestrado que perguntou: como desenvolver uma abordagem pedagógica mais inclusiva no ensino junto aos alunos com dificuldades acentuadas de aprendizagem? O objetivo geral foi investigar como o design universal para aprendizagem pode contribuir para uma abordagem pedagógica mais inclusiva. Metodologicamente, combina a pesquisa narrativa com a pesquisa de desenvolvimento, sendo que o instrumento adotado foi a construção colaborativa de um mapa de atividades apoiado nos princípios DUA. Definiu-se como universo de pesquisa três salas de recursos descentralizadas, sendo que três professores de AEE foram os sujeitos de pesquisa. Os resultados foram: o alargamento da abordagem curricular com múltiplos meios de apresentação do conteúdo, a ampliação do grau de influência dos
\end{abstract}

* Professora doutora, titular do Programa de Pós- Graduação em Educação - USCS; orientadora do trabalho que gerou a pesquisa deste artigo.

** Egresso do mestrado (USCS) - título da dissertação: Práticas pedagógicas no campo do Atendimento Educacional Especializado: Contribuições do Design Universal para a Aprendizagem, Programa de Pós-Graduação em Educação, Mestrado Profissional, da Universidade Municipal de São Caetano do Sul, sobre orientação da professora Doutora Elizabete Cristina Costa-Renders. 
aprendizes no percurso curricular e o desenvolvimento de mapa de atividades fundamentado no DUA.

Palavras-chave: Dificuldades acentuadas de aprendizagem. Design universal para a aprendizagem. Educação especial inclusiva.

\begin{abstract}
It deals with the application of universal design for learning (UDL) in specialized educational care for students with accentuated learning difficulties. It is the result of a master's research that asked: how to develop a more inclusive pedagogical approach in teaching to students with accentuated learning difficulties? The overall objective was to investigate how universal design for learning can contribute to a more inclusive pedagogical approach. Methodologically, it combines narrative research with development research, and the instrument adopted was the collaborative construction of a map of activities supported by the UDL principles. Three decentralized resource rooms were defined as a research universe, with three AEE teachers being the research subjects. The results were: the extension of the curricular approach with multiple means of presenting the content, the expansion of the degree of influence of the learners in the curricular path and the development of an activity map based on the UDL.
\end{abstract}

Keywords: Accentuated learning difficulties. Universal design for learning. Special inclusive education.

\title{
INTRODUÇÃO
}

A inclusão escolar é uma realidade no sistema de ensino brasileiro desde a Constituição de 1988, quando há uma transição do modelo da escola especial segregadora para a transversalidade de educação especial no sistema regular de ensino por meio da garantia das condições de acessibilidade e do oferecimento do atendimento educacional especializado (AEE) nas escolas regulares ou em centros especializados. Este processo tem trans- 
formado as escolas brasileiras, mas também tem demandado o enfrentamento de novos e antigos desafios na escola. Um desses desafios é o fracasso escolar.

Essa pesquisa foi desenvolvida em rede de ensino pública, juntamente com três professores de educação especial que trabalham com alunos com dificuldades acentuadas de aprendizagem. Estes sujeitos tem um histórico de fracasso escolar, num cenário em que os estudos de Patto (2015) apontam a busca constante pela culpabilização de diferentes atores ou de justificativas para este fato, como a inadequação da clientela que vive nas camadas mais empobrecidas da sociedade à educação escolar, os aspectos da estrutura e funcionamento do sistema escolar e, por fim, as considerações sobre a má qualidade do ensino que se oferece a essas crianças. (PATTO, 2015). Objetivamente, a autora aponta três dimensões que justificariam o fracasso escolar na perspectiva de classe.

1. As dificuldades de aprendizagem escolar da criança pobre decorrem de suas condições de vida. [...] 2. A escola pública é uma escola adequada as crianças de classe média e o professor tende agir, em sala de aula, tendo em mente um aluno ideal. [...] 3. Os professores não entendem ou discriminam seus alunos de classe baixa por terem pouca sensibilidade e grande falta de conhecimento a respeito dos padrões culturais dos alunos pobres, em função de sua condição de classe média. (PATTO, 2015, ps. 144 -149).

Patto (2015) indica a necessidade de questionarmos essa ideia de que o fracasso escolar é culpa exclusiva do aluno (não cabe no sistema) ou da sua família (inadequada). A autora indica a necessidade da escola repensar o seu método de ensino para o aluno real (o existente em sua diferença) e romper com a fixação no aluno idealizado (comum). Na realidade, muitas vezes, esse fracasso escolar é produzido pelo sistema escolar ou, ainda que inconscientemente, pelos profissionais da área de educação. 
Torna-se necessário, portanto, refletirmos se a escola oportuniza o conhecimento de forma democrática para todos os alunos. Tal perspectiva nos leva aos estudos de Pierre Bourdieu sobre a reprodução escolar de um determinado capital cultural. Quando comparamos a classe mais empobrecida com a classe mais favorecida, mesmo quando os alunos estão num espaço comum e participam da mesma aula, há muita diferença na forma como eles recebem a mesma informação. Ali revela-se a desigualdade. Segundo Nogueira,

Onde se via igualdade de oportunidades, meritocracia, justiça social, Bourdieu passa a ver reprodução e legitimação das desigualdades sociais. A educação, na teoria de Bourdieu, perde o papel que lhe fora atribuído de instância transformadora e democratizadora das sociedades e passa a ser vista como uma das principais instituições por meio da qual se mantêm e se legitimam os privilégios sociais. (NOGUEIRA, 2002, p. 17).

A cultura nos remete aos valores, crenças, hábitos e significados que cada pessoa adquire. Esse conjunto normalmente varia entre os diferentes grupos da sociedade. Assim como podemos herdar um capital financeiro, um patrimônio, uma propriedade, um valor em dinheiro, isso também acontece com a nossa cultura, nós herdamos um capital cultural. Quem detém o capital cultural hegemônico é privilegiado na escola por atender as expectativas do aluno ideal (universal).

Nas casas dos alunos de classes desfavorecidas economicamente, nem sempre há acesso com ao capital cultural privilegiado na escola, seja por meio de livros, revistas, jogos educativos, materiais escolares, visita a locais culturais (museus, galerias de arte, teatro, cinema, bibliotecas) e viagens. Deste modo, quando pessoas de diferentes classes sociais estão presentes no mesmo ambiente escolar, recebendo a mesma informação, parte delas 
não consegue dominar o código cultural apresentado e valorizado pela escola, devido a essa diferença de herança cultural entre as classes.

Em conversas com profissionais da área de educação, percebemos que o grande desafio da escola é ter um método de ensino acessível com uma abordagem interessante, envolvente, com diferentes formas de apresentação, ação, expressão e avaliação para todos alunos. Neste cenário, coloca-se a relevância desta pesquisa que busca pela aplicação dos princípios do design universal para aprendizagem nas práticas do AEE junto às crianças com dificuldades acentuadas de aprendizagem visando ao currículo acessível.

No contexto de construção da escola inclusiva, o design universal para a aprendizagem se apresenta como uma abordagem curricular mais inclusiva. Partindo dos estudos da neurociência aproximados à educação especial, como fruto do trabalho de um grupo de pesquisadores do CAST (2018), esta abordagem curricular propõe múltiplos modos de apresentação, de ação/ expressão e de engajamento no percurso escolar.

Deste modo, essa pesquisa partiu da pergunta: como desenvolver uma abordagem pedagógica mais inclusiva no processo de ensino aprendizagem junto ao grupo de alunos com dificuldades acentuadas de aprendizagem? O objetivo geral foi investigar como design universal para aprendizagem ${ }^{1}$ pode contribuir para a superação de barreiras de aprendizagem no trabalho junto aos alunos com dificuldades acentuadas de aprendizagem. Para alcançar este objetivo, em conjunto com os professores, buscamos constituir meios pedagógicos para a eliminação de barreiras no processo de ensino aprendizagem de alunos com dificuldades acentuadas de aprendizagem e desenvolver um objeto de aprendizagem que contribua para o êxito acadêmico dos alunos com dificuldades acentuadas de aprendizagem.

1 Doravante design universal para a aprendizagem, pois optei por preservar o campo semântico do termo design (inglês), por entender que o termo desenho (português) não representa o campo semântico do original. 


\section{UM RELATO DE EXPERIÊNCIA: \\ O ATENDIMENTO EDUCACIONAL ESPECIALIZADO NAS ESCOLAS REGULARES}

Após seis anos de trabalho dentro de escolas especiais, atendendo a alunos com deficiência intelectual, em 2008, iniciei uma nova etapa em minha carreira no serviço público municipal - passei a atuar como professor de educação especial, desenvolvendo trabalho no atendimento educacional especializado (AEE). Chegando na escola, a diretora me recebeu e conversou comigo para saber mais sobre minha experiência na educação especial. Depois seguimos andando pela escola até ao local em que eu iria trabalhar: a sala de recursos multifuncional. No ano em que ingressei nesta rede, essa unidade escolar fazia parte de um complexo, onde havia também uma escola de educação especial. Ou seja, ali, o antigo e o novo modelo desenvolviam-se paralelamente.

$\mathrm{O}$ atendimento educacional especializado nas escolas regulares está presente nas políticas educacionais brasileiras há mais de trinta anos. A Constituição de 1988, no seu artigo 208, no inciso III, menciona a oferta o atendimento educacional especializado aos alunos com deficiência preferencialmente na rede regular de ensino. Mas, no ano de 2008, neste mesmo complexo da rede pública municipal havia alunos com deficiência que estudavam no ensino regular comum (com o apoio do atendimento educacional especializado) e alunos com deficiência que estudavam em uma escola especial (sendo o atendimento educacional especializado oferecido de forma substitutiva ao ensino regular comum).

Percebi que o complexo educacional em que eu estava iniciando os meus trabalhos, ainda, contava com a participação de alunos com deficiência e com transtorno os globais do desenvolvimento estudando em duas realidades bem diferentes - na escola especial e em salas de AEE.

Os atendimentos aconteciam de segunda a quinta feira. Às sextas feiras eram reservadas para planejamento e formações 
oferecidas para os professores que atuavam no atendimento educacional especializado no ensino regular. Durante as formações de sexta feira, consegui compreender melhor o que era o atendimento educacional especializado e o que se esperava que estivéssemos desempenhando nas salas de recursos multifuncionais com os alunos.

Em uma dessas reuniões foi apresentado ao grupo de professores o Decreto $\mathrm{n}^{\circ}$ 6.571, promulgado em setembro de 2008, que dispunha sobre o atendimento educacional especializado.

Nos anos que seguiram a esse decreto, consegui ver e experimentar algumas de suas disposições. Por exemplo, eu trabalhava em um espaço que não tinha muitos recursos, mas depois da adesão do município ao Programa de Implantação de Salas de Recursos Multifuncionais do governo federal, a sala passou a ser denominada sala de recursos multifuncional. Este espaço recebeu todos os equipamentos mencionados no Manual de Orientação do Programa de Implantação de Salas de Recursos Multifuncionais (BRASIL, 2010).

Esses equipamentos e mobiliários ajudaram muito para que eu pudesse desempenhar melhor o AEE no contraturno na escola regular. A escola que atuava também recebeu uma verba do governo federal para adequação arquitetônica e acessibilidade, a partir dos meus estudos colaborei com sugestões para a elaboração de um plano. Tudo estava claro sobre o atendimento educacional especializado, onde ele deveria ser realizado, em qual horário, que não poderia ser substitutivo conforme disposto na Resolução CNE/CEB n. 4/2009.

Com o passar do tempo minha atenção começou a se dividir entre os alunos com deficiência, transtornos globais do desenvolvimento ou de altas habilidades/superdotação e os alunos que não têm diagnóstico. Eles estão nas escolas e não conseguem aprender, apresentando dificuldades acentuadas de aprendizagem.

Em meu trabalho docente cotidiano, comecei a observar que alguns professores do ensino regular afirmavam que tinham 
alunos que não conseguiam aprender, apontando que a família não colaborava nos estudos da criança, estava sempre ausente. E mais... Esses pais e responsáveis sequer conseguiam falar corretamente e tinham preferências musicais e hábitos de vestimenta pouco aceitáveis. Isto muito me incomodava.

Eles partiam do princípio da existência de uma cultura universal e de um padrão exclusivo que deveria ser seguido por todos que frequentassem os espaços escolares. Era comum mencionarem a situação econômica desfavorecida das famílias como elemento responsável pelo desempenho abaixo da média desses alunos. Em alguns casos, levantavam a hipótese dessa dificuldade advir de alguma causa genética, algum distúrbio, citando que o mesmo fato já tinha acontecido com o irmão mais velho que estudou na mesma escola ou, até mesmo, um primo. Enfim, deduziam que estes alunos deveriam ter alguma necessidade educacional especial, alguma dificuldade de aprendizagem, pois até quando eram encaminhados para programa de apoio à aprendizagem, com aulas complementares, o reforço escolar não obtinha avanços. Eu discordava dessas afirmações e hipóteses levantadas por esses profissionais e perguntava como poderia romper com esse ciclo de estigmatização e exclusão.

Resgatando todas essas memórias e relacionando-as com as políticas educacionais, hoje, avalio ser importante definir o que são as "necessidades educacionais especiais" e mais especificamente o termo "dificuldades acentuadas de aprendizagem" me apoiando no ato legislativo do Conselho Nacional de Educação, Câmara de Educação Básica, por meio da Resolução N. 2/2001 de 11 de setembro de 2001.

A Resolução CNE/CEB N. 2/2001 utiliza a terminologia "necessidades educacionais especiais", definindo, no seu artigo $5^{\circ}$, quem são esses alunos e categorizando-os em três categorias. A saber, aqueles que apresentam: (I) dificuldades acentuadas de aprendizagem, (II) dificuldades de comunicação e sinalização e (III) grande facilidade de aprendizagem. 
A referida resolução classifica as pessoas com dificuldades acentuadas de aprendizagem em dois grupos, um vinculado à deficiência, limitações e disfunções e outro não vinculado a uma causa orgânica específica, como deficiência, limitações e disfunções. Ou seja, relaciona-se a terminologia "dificuldades acentuadas de aprendizagem" tanto às pessoas com deficiência, limitações e disfunções quanto às que não tem uma causa orgânica específica.

\section{O DESIGN UNIVERSAL PARA APRENDIZAGEM COMO UMA ABORDAGEM CURRICULAR MAIS ACESSÍVEL}

O relato de experiência acima apresentado coloca em destaque a fase de transição da educação especial substitutiva para a educação especial como modalidade transversal em todo o sistema escolar que se apresente como inclusivo. Além disso, aponta para o problema do que seriam necessidades educacionais especiais e do ato de nomear o público alvo do atendimento educacional especializado, pois há sujeitos que não se adequam ao marco legal tal qual está posto. A inclusão escolar continua demandando, portanto, a superação do reducionismo curricular, sejam eles firmados no capital cultural privilegiado ou no aluno universal idealizado.

Zerbato e Mendes (2018) apontam o problema da adoção, pelas escolas, de um currículo fixo e limitado, projetado para um aluno idealizado, categorizando aqueles que não conseguem alcançar os conteúdos desejados como alunos com dificuldades acentuadas de aprendizagem. Com o objetivo de transformar esses ambientes em ambientes favoráveis à aprendizagem de todos e cada um, foi desenvolvido, em Massachusetts, no ano de 1999, por David Rose, Anne Meyer e outros pesquisadores do Center for Applied Special Tecnology (CAST), a proposta do Universal Designer for Learning (UDL). No Brasil, o termo é traduzido para Desenho Universal para a Aprendizagem (DUA). Esta aborda- 
gem curricular consiste na elaboração de estratégias visando à remoção de barreiras para que todos possam aprender, minimizando a necessidade de adaptação curricular para um indivíduo (ROSE; MEYER, 2014).

Neste texto, aproximamos os princípios do design universal para aprendizagem à prática pedagógica dos professores de AEE que trabalham em sala de recursos multifuncionais com alunos com dificuldades acentuadas de aprendizagem. Temos em perspectiva que, apoiados nos princípios do DUA, possamos romper com os reducionismos e a exclusão escolar dos alunos com dificuldades acentuadas de aprendizagem. Nos distanciamos da culpabilização destes sujeitos e nos aproximamos dos processos de construção das condições de acessibilidade pedagógica e curricular na escola e nas salas de recursos descentralizadas.

$\mathrm{Na}$ perspectiva do design universal para a aprendizagem, ao elaborar recursos pedagógicos, devemos priorizar o critério da acessibilidade, sendo os conteúdos trabalhados acessíveis a todos e a cada um. O design universal para a aprendizagem se apresenta como uma abordagem curricular inclusiva que busca apoiar os profissionais da educação, especialmente, os professores. Trata-se de

[...] uma abordagem curricular que procura ajudar os docentes a: i) responder às necessidades de diversos alunos; ii) remover as barreiras à aprendizagem; iii) flexibilizar o processo de ensino; iv) permitir aos alunos formas alternativas de acesso e envolvimento na aprendizagem e. por último, v) reduzir a necessidade de adaptações curriculares individuais, contribuindo assim para o desenvolvimento de práticas pedagógicas inclusivas. (NUNES, 2015, p. 140).

Buscamos analisar os objetos de aprendizagem utilizados na prática pedagógica de professoras que atuam em salas de recursos descentralizadas, localizadas em duas escolas em diferentes 
regiões da mesma cidade. Para tal, fizemos uso da pesquisa de desenvolvimento, pautando o processo de construção de um objeto de aprendizagem juntamente com as professoras, pois

[...] o problema nasce de uma proposta de solução revelada como de interesse genuíno e relativo a um processo cognitivo, validada tanto pela comunidade engajada na práxis em questão uma escola, uma comunidade de aprendizagem como pelo investigador, que de fato assume a posição de pertencer a esta comunidade. (MAT'TA, 2014, p. 29).

Nesta perspectiva, organizamos os procedimentos que foram desenvolvidos na pesquisa de campo. As fases e os procedimentos neste percurso podem ser visualizadas no quadro 1.

\section{Quadro 1 - Fases e procedimentos}

\begin{tabular}{|c|c|}
\hline Fase & Procedimento \\
\hline $\begin{array}{l}\text { Fase "A" } \\
\text { • Estudo documental e bibliográfico }\end{array}$ & $\begin{array}{l}\text { Fase "A" } \\
\text { • Organização do grupo de traba- } \\
\text { lho para os estudos sobre o DUA } \\
\text { e objetos de aprendizagem }\end{array}$ \\
\hline $\begin{array}{l}\text { Fase "B" } \\
\text { • Experiência Piloto do Pesquisador }\end{array}$ & $\begin{array}{l}\text { Fase "B" } \\
\text { • Aplicação dos princípios do } \\
\text { DUA nas estratégias pedagógicas } \\
\text { utilizadas pelo pesquisador com } \\
\text { seu grupo de alunos. }\end{array}$ \\
\hline $\begin{array}{l}\text { Fase "C" } \\
\text { • Construção de quadro interativo } \\
\text { entre alunos, com base no DUA. }\end{array}$ & $\begin{array}{l}\text { Fase "C" } \\
\text { • Trabalho conjunto com em três } \\
\text { reuniões de planejamento. }\end{array}$ \\
\hline $\begin{array}{l}\text { Fase "D" } \\
\text { • Construção do mapa de atividades } \\
\text { com base nos princípios do DUA. }\end{array}$ & $\begin{array}{l}\text { Fase "D" } \\
\text { • Realização dos três ciclos de } \\
\text { aplicação/análise/avaliação para } \\
\text { validação do mapa de atividades } \\
\text { com base no DUA. }\end{array}$ \\
\hline
\end{tabular}

Fonte: Elaborado pelos autores, 2020. 
Esta pesquisa foi teoricamente orientada pelo design universal para a aprendizagem, sendo que esta proposta teórica serviu como fundamento para a construção de um objeto de aprendizagem. Antes da construção desse objeto de aprendizagem, o grupo de professores precisou estudar sobre o design universal para a aprendizagem e sobre a caracterização de um objeto de aprendizagem.

Trabalhamos a prática escolar buscando a remoção de barreiras pedagógicas de uma forma mais rápida e impactante. Desta forma, quando o grupo de trabalho, composto por professores de AEE, realizou as intervenções em campo, estávamos atentos aos sete apontamentos de Nelson (2013), citados por Zerbato e Mendes (2018). A saber. A aprendizagem está relacionada com aspectos emocionais e biológicos dos indivíduos; durante as intervenções, os alunos, além de terem experiências significativas, precisaram de tempo e oportunidade para explorar o conhecimento recém adquirido; as emoções motivaram os alunos a aprender e a conhecer; os conhecimentos adquiridos nas intervenções precisaram ser apreendidos e estes foram utilizados e transferidos para outros ambientes; o conhecimento novo teve sentido para o sujeito interligando com o que ele já sabia para que ocorresse a aprendizagem e não somente uma memorização; cada pessoa é única, assim cada um tem o seu ritmo, estilo e modo de aprendizagem e, por último, a aprendizagem apropriada ocorreu com desafio e não inibida com ameaças, pois os alunos precisaram tanto de estabilidade quanto de desafio.

$\mathrm{Na}$ última etapa do desenvolvimento do objeto de aprendizagem, as professoras participantes da pesquisa e o pesquisador atentaram-se também para o que Zerbato e Mendes (2018) descrevem sobre os três grandes sistemas corticais do cérebro envolvidos na aprendizagem, que são as redes de reconhecimento, redes estratégicas e redes afetivas.

Nesta pesquisa, outro conceito que o grupo de professores precisou dominar foi objeto de aprendizagem. Segundo Braga 
(2014), trata-se de "qualquer entidade, digital ou não, que pode ser usada reutilizada ou referenciada durante o aprendizado apoiado pela tecnologia”. (2014, p. 21). Essa definição se tornou importante porque, durante as reuniões com o grupo de professores, desenvolvemos um objeto de aprendizagem não digital.

Os objetos de aprendizagem possuem duas dimensões, a pedagógica e a técnica (BRAGA, 2014). A pedagógica nos remete a cinco características: interatividade, autonomia, cooperação, cognição e afetividade. Já, a dimensão técnica aponta para outras doze características de um objeto de aprendizagem: disponibilidade, acessibilidade, confiabilidade, portabilidade, facilidade de instalação, interoperabilidade, usabilidade, manutenibilidade, granularidade, agregação, durabilidade e reusabilidade.-

\section{NOVOS HORIZONTES EPISTEMOLÓGICOS: APLICANDO O DUA NA SALA DE RECURSOS}

As professoras participantes da pesquisa relataram que, embora tenham sido trabalhadas todas as etapas do mapa de atividade com o tema "correspondência", na hora de escrever a carta, os alunos apresentaram dificuldades em imaginar o que eles poderiam escrever. Elas precisaram fazer perguntas e sugestões para os alunos, por exemplo: "Quando conhecemos um novo amigo na escola, o que nós fazemos primeiro?” Neste momento, algumas das respostas dos alunos foram:

"Eu digo oi. Meu nome é ____. Como é o seu nome?" "Oi meu nome é ___ tenho ___ anos. E você qual seu nome? Quantos anos você tem?" "Eu falo oi, e pergunto: Qual é o seu time de futebol?" "Eu falo oi e pergunto do que ele gosta de brincar." (Diário de Pesquisa, Conjunto de Relatos n.2)

Com essas respostas, as professoras explicaram aos alunos que a situação de uma conversa informal real e corriqueira, que 
ocorre de forma presencial, poderia ser transportada para a escrita, numa conversa a distância, no formato de carta. Assim, os alunos começaram a ter mais elementos para escrever as suas cartas.

No primeiro ciclo de aplicação, análise e avaliação do mapa de atividade (com o tema correspondência), avaliamos que faltou serem oferecidas informações de como escrever uma carta. Nos perguntamos: por que não podemos apresentar diferentes cartas, em diferentes formas, para os alunos? Poderíamos ter feito da mesma forma como foi realizado com o preenchimento do envelope, oferecer a exibição de vídeos curtos com explicações, mais a confecção de cartazes junto com os alunos, construindo um roteiro. Nesse roteiro, poderia ter todas as informações que os alunos precisaram, por exemplo: identificação da cidade e a data; saudação utilizando o nome do destinatário; apresentação do remetente, com informações adicionais como o nome completo, nome da escola que estuda, série, bem como informações sobre suas preferências e brincadeiras.

O segundo ciclo de aplicação consistia no preenchimento do envelope pelos alunos, com suas informações pessoais: nome completo, endereço e código de endereçamento postal - CEP. Nesse momento, as professoras perceberam que a maioria deles não sabia o seu endereço, alguns sabiam o nome da cidade, poucos o nome do bairro e uma criança, que morava próximo à escola, não sabia o seu endereço. Mas ela conseguia explicar onde morava, descrevendo alguns pontos de referência perto da sua casa, por exemplo, o "escadão", o mercado e o lugar que arruma carro. Nenhum dos alunos sabia o que era CEP e nem a sua função.

Isso deixou as professoras muito preocupadas, sendo necessário que ambas trabalhassem o endereço completo dos alunos. Isto seria importante não só para a realização da atividade, mas como conhecimento para a vida cotidiana deles. Trata-se da perspectiva do letramento, como a prática social da leitura e escrita (SOARES, 2003).

O terceiro ciclo de aplicação/análise/avaliação para validação final do mapa de atividades (nosso objeto de aprendizagem) consistia no acesso dos alunos às correspondências endereçadas a eles, as quais foram depositadas na caixa de cartas, confeccionada 
na sala de recursos descentralizada. Eles deveriam ler e escrever a devolutiva. Nesse momento, aquela criança que ao invés de escrever para outra criança, escreveu para uma funcionária da escola, não conseguiu localizar a sua resposta. Ao escrever a identificação da criança no envelope, a funcionária escreveu utilizando a letra cursiva, detalhe que a professora não percebeu. No dia do atendimento, a aluna chegou, abriu a caixa de cartas e foi procurar seu nome entre os envelopes que lá estavam. Todavia, essa criança sabia reconhecer o seu nome somente na letra bastão. Ao procurar, ela passou todos os envelopes duas vezes, inclusive o endereçado a ela, mas escrito com letra cursiva. Ela não conseguia identificar. Neste cenário, deveriam ser oferecidas opções para o uso da linguagem (CAST, 2018). Neste caso específico, a escrita utilizada, a letra cursiva, não era acessível para essa criança.

Nesse momento, a professora participante da pesquisa, percebeu a barreira imposta à criança por um código que ela não conhecia e explicou para a criança as diferentes formas de se escrever. Apresentou, na lousa, a escrita do nome da criança, utilizando a letra bastão, comparando com a escrita em letra cursiva. Depois dessas explicações, a aluna fez uma nova busca entre as cartas e, fazendo a comparação com os nomes escritos na lousa, conseguiu identificar e abrir a sua correspondência.

Como o terceiro ciclo de aplicação estava próximo ao fim do ano letivo, as respostas dos alunos para quem havia lhes enviado a carta e o cartão precisou ser feita por meio da gravação de vídeo. Avaliamos esta ação como interessante, pois oportunizou-se mais uma estratégia do campo dos multiletramentos, oferecendo mais uma opção de expressão (CAST, 2018) no processo de comunicação.

Analisando os resultados do processo da pesquisa aplicada em campo em conjunto com as duas professoras participantes da pesquisa, consideramos que contemplamos o princípio das redes estratégicas (CAST, 2018), ligadas à ação e expressão, pois oportunizamos múltiplas formas de comunicação, na execução do mapa de atividades, com o tema "correspondência" apoiado no design universal para a aprendizagem. A complexidade e 
exigência dos textos escritos foi variável de acordo com a etapa de alfabetização de cada aluno. Eles produziram desde textos simples, com o apoio do professor como seu escriba, até textos mais complexos produzidos por eles mesmos, apenas, com a intervenção do professor focada na revisão do texto e organização das ideias.

Concluímos que também conseguimos aplicar os múltiplos modos de apresentação neste mapa de atividades. Oferecemos múltiplas mídias, aproveitamos o relato oral dos responsáveis pelos alunos, confeccionamos cartazes escritos e ilustrados sobre o tema e, ainda, produzimos pequenos vídeos.

Como consequência desse processo conjunto de planejamento das atividades com base no design universal para a aprendizagem, os alunos demonstraram maior interesse, pois eles tinham a responsabilidade de escrever para outra pessoa, dentro de um contexto de comunicação real. Isto resultou em um maior engajamento daqueles que, antes, tinham muitas ressalvas em escrever.

O produto final deste processo colaborativo com as professoras numa pesquisa narrativa, foi um objeto de aprendizagem a ser utilizado por professores e professoras que pretendam aplicar os princípios do design universal para aprendizagem como estratégia pedagógica. Nós o desenvolvemos com o objetivo de oferecer uma ferramenta de apoio que auxilie professores na remoção de barreiras no processo de ensino aprendizagem. Especificamente, esta investigação trabalhou no sentido do êxito acadêmico dos alunos com dificuldades acentuadas de aprendizagem. Todavia, este objeto de aprendizagem está aberto para aplicação no trabalho com todos os alunos, sem distinção. Trata-se de um Mapa de Atividades do Projeto Correspondência.

$\mathrm{Na}$ construção deste mapa de atividades, seguimos os princípios do design universal para a aprendizagem (CAST, 2006), considerando os múltiplos modos de (i) apresentação, de (ii) ação e expressão e de (iii) envolvimento no processo de ensino aprendizagem. Durante o desenvolvimento desse objeto de aprendizagem também foi considerada a variabilidade das três redes neurais de aprendizagem (de reconhecimento, estratégicas e 
afetivas), nas quais o design universal para aprendizagem (CAST, 2018) se fundamenta.

Devido ao objetivo e espaço deste texto, aqui, não é possível apresentar o mapa do projeto correspondência. Deste modo, fizemos uma adaptação deste mapa e o apresentamos no quadro 2.

\section{Quadro 2 - Mapa de Atividades com base no DUA}

Uma estratégia pedagógica baseada no design universal para aprendizagem

Considera os princípios do design universal para aprendizagem: oferecer múltiplos modos de apresentação dos conteúdos, considerar as múltiplas possibilidades de ação/expressão e oportunizar os múltiplos modos de engajamento no processo de ensino aprendizagem. Tema:

Objetivo:

\begin{tabular}{|c|c|c|}
\hline \multicolumn{3}{|c|}{ DESENVOLVIMENTO DAS ATIVIDADES } \\
\hline \multicolumn{3}{|c|}{ Primeira aplicação - Atividade 1} \\
\hline Proposta de atividade & $\begin{array}{l}\text { Múltiplos meios utilizados } \\
\text { - como a variabilidade foi } \\
\text { respeitada? }\end{array}$ & $\begin{array}{l}\text { Quais os problemas iden- } \\
\text { tificados? }\end{array}$ \\
\hline \multicolumn{3}{|l|}{ Atividade 1a:. } \\
\hline Atividade 1b: & . & \\
\hline \multicolumn{3}{|l|}{ Atividade 1c: } \\
\hline \multicolumn{3}{|c|}{ Segunda aplicação - Atividade 2} \\
\hline Atividade revista & $\begin{array}{l}\text { Múltiplos meios utilizados } \\
\text { - como a variabilidade foi } \\
\text { respeitada? }\end{array}$ & $\begin{array}{l}\text { Quais os problemas ainda } \\
\text { identificados? }\end{array}$ \\
\hline \multicolumn{3}{|l|}{ Atividade 2a:. } \\
\hline Atividade $2 \mathrm{~b}$ : & . & \\
\hline \multicolumn{3}{|l|}{ Atividade 2c: } \\
\hline \multicolumn{3}{|c|}{ Terceira aplicação - Atividade 3} \\
\hline Atividade finalizada & $\begin{array}{l}\text { Múltiplos meios utilizados } \\
\text { - como a variabilidade foi } \\
\text { respeitada? }\end{array}$ & $\begin{array}{l}\text { Quais os problemas solu- } \\
\text { cionados? }\end{array}$ \\
\hline \multicolumn{3}{|l|}{ Atividade 3a: } \\
\hline \multicolumn{3}{|l|}{ Atividade 3b: } \\
\hline Atividade 3c: & & \\
\hline
\end{tabular}

Fonte: Elaborado pelos autores, 2020. 


\section{CONSIDERAÇÕES FINAIS}

Os participantes dessa pesquisa tiveram a oportunidade de rever o seu processo de ensino e criar novas possibilidades baseados nos três princípios orientadores do design universal para a aprendizagem (DUA). Os estudos sobre essa abordagem pedagógica nos auxiliaram no processo inclusivo, desde a aplicação da experiência piloto, passando pelas reuniões de planejamento até a aplicação dos ciclos de validação, em conjunto com as professoras participantes da pesquisa. Evidenciou-se como os princípios do design universal para a aprendizagem contribuem para a construção de uma abordagem curricular mais inclusiva também no trabalho com alunos com dificuldades acentuadas de aprendizagem.

Especialmente, buscamos aplicar os múltiplos modos de apresentação, múltiplos modos de engajamento e múltiplos modos de ação e expressão no planejamento e no desenvolvimento de um mapa de atividades relacionado ao projeto correspondência. Conseguimos constituir novos meios pedagógicos para a remoção de barreiras no processo de ensino aprendizagem dos alunos com dificuldades acentuadas de aprendizagem.

Estávamos mais atentos ao engajamento e interesse dos alunos, incrementamos nossas apresentações com exibição de vídeos e áudios sobre o tema a ser estudado. Especialmente, a utilização do recurso do Google Maps oportunizou o engajamento dos alunos na resolução de um problema - saber onde moro. Foi perceptível que os alunos passaram a ler ou realizar as atividades com outra motivação. Ou seja, a nova proposta metodológica oportunizou um grau maior de envolvimento por parte dos estudantes. Isso foi possível porque, no processo todo, estávamos atentos às situações, observando os comportamentos e interesses dos alunos, identificando o que eles gostavam e avaliando o que eles desejavam saber mais.

Em todas as situações pedagógicas, procuramos trabalhar uma abordagem curricular que respeitasse a variabilidade das 
redes neurais de aprendizagem. Para conseguir realizar isso, como grupo de pesquisa composto pelo pesquisador e pelas professoras, precisamos estudar, pesquisar, preparar e selecionar diferentes formas e formatos para oferecer o mesmo conteúdo para os alunos. Se o professor oferecer opções diferentes de apresentação do mesmo tema, ele ampliará as possibilidades de reconhecimento e engajamento de seus alunos.

Houve embates e desafios no processo, especialmente, nos momentos em que a escola não oferecia os recursos necessários para a aplicação do DUA. O que nos remete ao necessário reconhecimento de que a construção da escola inclusiva é uma tarefa da equipe escolar comprometida com uma rede de apoio à inclusão. Um professor ou professora não tem condições de transformar uma escola sozinho, são necessários os pilares de sustentação para a aplicação dos princípios do design universal para a aprendizagem em uma rede de ensino.

O mapa de atividade desenvolvido com base nos três princípios do design universal para a aprendizagem foi a ferramenta que modificou o processo de ensino e contribuiu para o êxito acadêmico dos alunos com dificuldades acentuadas de aprendizagem. Se o professor, numa rede de apoio à inclusão, constituir um processo de ensino com múltiplas opções de ações, expressões de experiências e avaliações, seu aluno terá escolhas e terá mais chances de mostrar o que ele sabe fazer. Com essas diferentes oportunidades, seu aluno poderá usar as estratégias nas quais se sente mais confortável e apresentará os melhores resultados.

Entendemos que é possível encontrar um caminho diferente para o ensino, um caminho mais inclusivo, onde todos realizem a sua jornada, podendo chegar ao mesmo destino, com a possibilidade de ter os resultados exitosos de uma maneira mais rápida e prazerosa. 


\section{REFERÊNCIAS}

BOURDIEU, Pierre. Capital Cultura, Escuela y Espacio Social. 2. ed. Buenos Aires: Siglo Veintiuno Editores, 2015.

BRAGA, Juliana Cristina. (Org). Objetos de Aprendizagem: Volume 1 - Introdução e Fundamentos. . Santo André, Editora da UFABC, 2014.

BRASIL. Constituição da República Federativa do Brasil. Brasília: DF, 1988.

BRASIL. Decreto n. 6.571, de 17 de setembro de 2008. Dispõe sobre o atendimento educacional especializado. Brasília: DF, 2008

BRASIL. Ministério da Educação. Resolução 02/2001 da CEB/CNE, que institui as Políticas Nacionais para a Educação Especial na Educação Básica. Brasília: DF, 2001.

BRASIL. Ministério da Educação. Secretaria de Educação Especial. Resolução 04/2009 da CEB/CNE, que institui Diretrizes Operacionais para o Atendimento Educacional Especializado na Educação Básica, modalidade Educação Especial. Brasília: DF, 2009.

BRASIL. Ministério da Educação. Manual de orientações: Programa de Implantação de Sala de Recursos Multifuncional. Brasília: MEC/SEESP, 2010.

CAST UDL. Learn About Universal Design for Learning (UDL). 2006. Disponível em: http://bookbuilder.cast.org/learn.php. Acesso em: 30 dez. 2019.

CAST UDL. UDL e o cérebro do aprendizado. 2018. Disponível em: http://www.cast.org/our-work/publications/2018/udl-learning-brain-neuroscience.html. Acesso em: 30 dez. 2019.

MATTA, Alfredo Eurico Rodrigues, DA SILVA; Francisca de Paula Santos; BOAVENTURA, Edivaldo Machado. Design-Based Research ou Pesquisa De Desenvolvimento. In Revista da FAEEBA - Educação e Contemporaneidade, Salvador, v. 23, n. 42, p. 23-36, jul./dez. 2014.

NELSON, Loui Lord; ROSE, David Howard. Design and deliver: Planning and teaching using universal design for learning. Paul H. Brookes Publishing Company, 2013.

NOGUEIRA, Cláudio Marques Martins; NOGUEIRA, Maria Alice. A sociologia da educação de Pierre Bourdieu: limites e contribuições. Educação \& Sociedade, v. 23, n. 78, p. 15-36, 2002. 
NUNES, Clarisse; MADUREIRA, Isabel. Desenho Universal para a Aprendizagem: Construindo práticas pedagógicas inclusivas. Da investigação às práticas, v. 5, n. 2, p. 126-143, 2015.

PATTO, Maria Helena Souza. A produção do fracasso escolar: histórias de submissão e rebeldia. 4. ed. São Paulo: Intermeios, 2015.

ROSE, David H, MEYER, Anne \& GORDON, David. Design universal para aprendizado: A teoria e a prática. Wakefield, Massachusetts, 2014.

SOARES, Magda. Alfabetização e letramento. 7. ed. São Paulo: Contexto, 2003.

ZERBATO, Ana Paula; MENDES, Enicéia Gonçalves. Desenho universal para a aprendizagem como estratégia de inclusão escolar. Educação Unisinos, v. 22, n. 2, p. 147-155, 2018.

\section{SOBRE OS AUTORES}

\section{Elizabete Cristina Costa Renders}

Pós Doutora (2015) e Doutora em Educação (2012) na área de Ensino e Práticas Culturais pela UNICAMP, com tese desenvolvida sobre a educação inclusiva. Trabalha com a formação de professores no Programa de Pós-Graduação em Educação (mestrado profissional em Educação) da Universidade Municipal de São Caetano do Sul (2017-atual). É líder do grupo de pesquisa ACESSI (Acessibilidade escolar e inclusão social). Em suas pesquisas, destacam-se temas como: educação inclusiva, formação de professores, desenho universal para a aprendizagem, educação especial, Libras, direitos humanos e epistemologias emergentes.

elizabetecostarenders@gmail.com

\section{Augusto Santos Silva}

Mestre em Educação pela Universidade Municipal de São Caetano do Sul (2020), graduado em pedagogia pela Faculdade de São Bernardo (2003), com habilitação em Educação Especial na área de deficiência Intelectual pelo Centro Universitário Fundação Santo André (2005). É participante do grupo de pesquisa ACESSI (Acessibilidade escolar e inclusão social). Em suas pesquisas, destacam-se temas como: educação inclusiva, formação de professores, desenho universal para a aprendizagem, educação especial e dificuldades acentuadas de aprendizagem.

pedagogoaugusto@gmail.com 